\title{
Experimental research of indexes of operation of the combined fertilizing-sowing assembly unit
}

\author{
Ye.Petrychenko, \\ National Science Center «Institute of Mechanization and Electrification Agriculture» \\ * Scientific supervisor - Dr. Sc., academician of NAAS \\ V.M. Bulgakov, National University of Bioresources and nature use of Ukraine
}

The purpose. To justify expediency of overlapping production operations of sowing cereal crops and importing basic and starting doses of mineral fertilizers at application of the combined machine-tractor assembly unit. Methods. At study they use methods of field experiments with application of standard equipment. The design of experiments is realized with the use of correlation methods and methods of numerical calculations on PC. Results. Comparative study of quality of sowing barley while using basic and upgraded fertilizing-sowing assembly units have shown the following. Variation factor of depth of sowing seeds by basic assembly unit made $8,2 \%$ (by combined one $-4,7 \%$ ); equitability of seeds longwise the row for basic assembly unit was $63,8 \%$ (for improved one - $84,9 \%$ ); field germination rate of seeds at sowing by basic assembly unit made $80,4 \%$ (improved one $-87,4 \%$ ). Thus, application of the combined fertilizing-sowing assembly unit increased equitability of seeds longwise the row. Alongside with it increases field germination rate of seeds, and decreases variation factor of depth of sowing seeds in furrow. Conclusions. By results of field pilot researches increase of productivity of spring wheat and barley is fixed at application of the combined fertilizing-sowing assembly unit with simultaneous importation into soil of the basic dose of mineral fertilizers and sowing cereal crops with importation of starting dose of mineral fertilizers as compared to known schemes of such operations. The gained results confirm expediency of overlapping the specified production operations at one passage of the combined machine-tractor assembly unit.

Key words: combined assembly unit, seeder, mineral fertilizers, field experiments, quality factors, field germination rate, productivity.

Introduction. One of the ways to improve the efficiency of agricultural machinery in the production of crop production is the use of combined aggregates, in which several operations are performed in one pass. This will reduce the cost of labor and fuel consumption per unit of grown products, as well as reduce the effect on the soil of running systems of mobile machinery $[1,2,3,4,5,6]$.

High efficiency combined seeding units are produced by leading manufacturers of seed crops to increase the efficiency of sowing crops. But simultaneously with the increase of technological efficiency indicators, when applying combined seed aggregates, there is a need for the use of more powerful energy means (tractors), as well as their inherent high cost.

Therefore, the search for ways to increase the efficiency of sowing equipment is an urgent task in the field of mechanization of agrarian production.

\section{Analysis of recent research.}

In the formation of sowing aggregates, two main directions can be traced: the creation of units from single-use machines, as well as the creation of specialized aggregates. The practice of using aggregates made from separate machines allows to perform various technological operations if necessary, and the use of combined sowing aggregates, which perform several technological operations in one passage, allows to reduce the number of unit passes and consolidation of soil, increase the yield of crops, as well keep moisture $[1,2,3,4,5,6]$. 
On the basis of analysis of agrotechnological peculiarities of agricultural crop sowing in order to solve the problem of finding ways to increase the efficiency of seed machinery, it is suggested, in the case of grain crops, to combine its implementation with the introduction of the starting and main dose of mineral fertilizers using a two-engine combined seed aggregate formed with the use of a tractor of a pulling class 1.4 based on two corn blubber seeders.

The purpose of the study is to experimentally substantiate the feasibility of combining the technological operations of grain crop sowing and introducing the starting and main dose of mineral fertilizers in the application of a combined sowing unit.

Research methodology. For the experimental study of the feasibility of combining the grain sowing process and introducing the starting and main dose of mineral fertilizers, a field experiment was conducted and in production conditions on experimental fields of the Experimental farm "Olenivske" of the Fastovsky district of the Kyiv region in the sowing of spring wheat and barley according to known methods $[7,8,9]$. The conditions for conducting field trials were determined according to existing methods and consist of: preliminary cultivation - pre-sowing cultivation, type of soil - chernozem, field relief - even, microrelief - leveled, soil moisture: in the layer $0 \ldots 5 \mathrm{~cm}-17.4 \ldots 18.7 \%$ in the layer $5 \ldots 10$ $\mathrm{cm}-20.1 \ldots 22.3 \%$, the hardness of the soil: in the layer $0 \ldots 5 \mathrm{~cm}-0,20 \ldots 0,35 \mathrm{MPa}$, in a layer $5 \ldots 10$ $\mathrm{cm}-1,38 \ldots 1,57 \mathrm{MPa}$, inflorescence of the field $-13 \mathrm{~g} / \mathrm{sq} . \mathrm{m}$. The research was carried out on an experimental plant - a combined sowing unit, which was formed from two grain-seeded drills (Fig. 1).

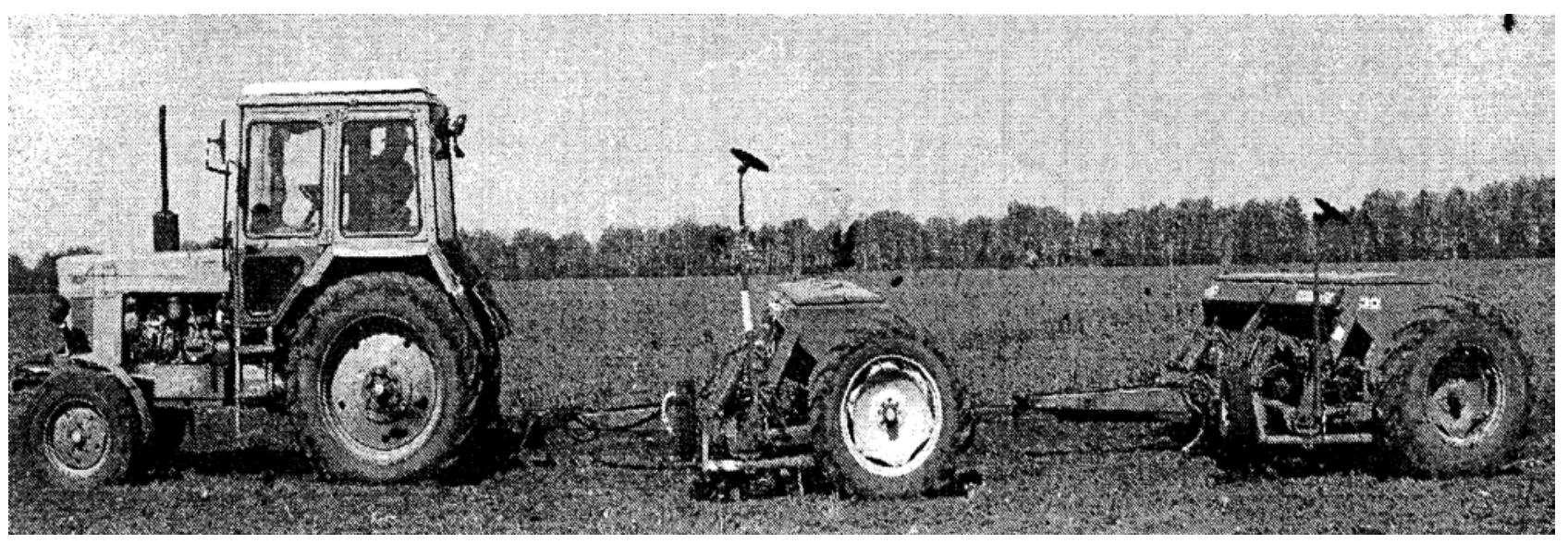

Fig. 1 - General view of the experimental installation

The first seeder of the seed aggregate provides an intravenous introduction of the required starting dose of mineral fertilizers to the required depth with an intermediate row of $25 \mathrm{~cm}$, and the second - the seeding of grain crops to the appropriate depth with an intermediate row of $12.5 \mathrm{~cm}$ with the simultaneous introduction of the main dose of mineral fertilizers. For the aggregation of seeders among themselves and with the tractor a special coupling was designed and manufactured, the application of which will allow for the necessary maneuverability of the combined aggregate during operation and transportation [Patent].

For experimental sowing in this field, areas were allocated that were sown during one day according to the following schemes: 1) with pre-planting of soil without introduction of granulated mineral fertilizers (control); 2) with a continuous surface introduction of the starting dose of fertilizers, pre-sowing cultivation and seeding of seeds with the simultaneous introduction into the soil of the main dose of fertilizers; 3 ) standard pre-planting of soil and seed of seeds with the simultaneous introduction of soil to the starting and main dose of fertilizers.

The seeding process with a combined aggregate was carried out at a seeding depth of $5 \mathrm{~cm}$, a fertilization depth of $8 \mathrm{~cm}$ with a sowing speed of $10 \mathrm{~km} / \mathrm{h}(2.78 \mathrm{~m} / \mathrm{s})$, which was based on the results of previous laboratory field experiments. The estimation of efficiency of sowing was carried out on the size of yield (c / ha), which was determined according to the standard method in the period of full maturity 
of grain crops by their manual harvesting from the area which is limited to the frame of $1 \mathrm{~m} \times 1 \mathrm{~m}$ and then weighing.

In addition, experimental studies were carried out on the comparison of sowing efficiency with basic and upgraded sowing aggregates. Indicators of efficiency of sowing accepted coefficient of variation of seed depth (\%), uniformity of seed distribution in a row (\%) and seed similarity (\%). To do this, in the process of sowing, the wraps were lifted, and by measuring five points of the field with a fivefold repetition, they controlled the depth of seeding and the number of seeds per 1 linear meter of the line, and after receiving the stairs a row was opened at five points of the field and determined the number of sprouted and not germinated seeds.

Research results. In conducting comparative field experiments on barley sowing quality with basic and upgraded sowing units in accordance with the accepted method, the following values of qualitative indices were obtained.:

- the coefficient of variation of the seed depth of the base unit was $8.2 \%$, and the combined $-4,7 \%$;

- the uniform distribution of seed along the length of the line for the base unit $-63.8 \%$, for the modernized $-84,9 \%$;

- field similarity of seeds with sowing of the basic unit is $80.4 \%$, modernized $-87,4 \%$.

Thus, on the basis of the analysis of the data of the results of the research, it was established that the application of the combined sowing aggregate will significantly increase the uniform distribution of the seed along the length of the line. At the same time, the seed germinability will increase, and the coefficient of variation in the depth of seed placement in the furrow will decrease. The obtained data of experimental researches confirm improvement of quality of sowing performance when combining technological operations with combined sowing aggregate. At the same time, it was established that during the operation of the combined aggregate in the field conditions possible flaws in the mutual placement of the passage lines of two seeders of the unit due to imperfection of the coupling construction.

Experiments were conducted to substantiate the feasibility of combining the above-mentioned technological operations in one passage of the unit. For this purpose, experimental plots were allocated on the field, which carried out seeding of spring wheat and barley in three main schemes:

1) sowing after cultivation without fertilization (control = scheme l);

2) the continuous introduction of the starting norm of mineral fertilizers by the spreading method + presowing cultivation + combined sowing with simultaneous introduction of the basic norm of fertilizers (scheme II);

3) pre-sowing cultivation + combined sowing with experimental sowing unit with simultaneous introduction of the starting and main fertilizer standards (scheme III).

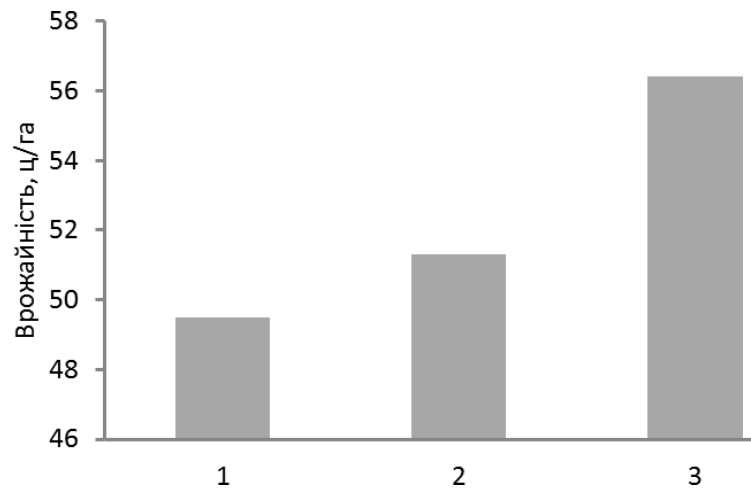

a)

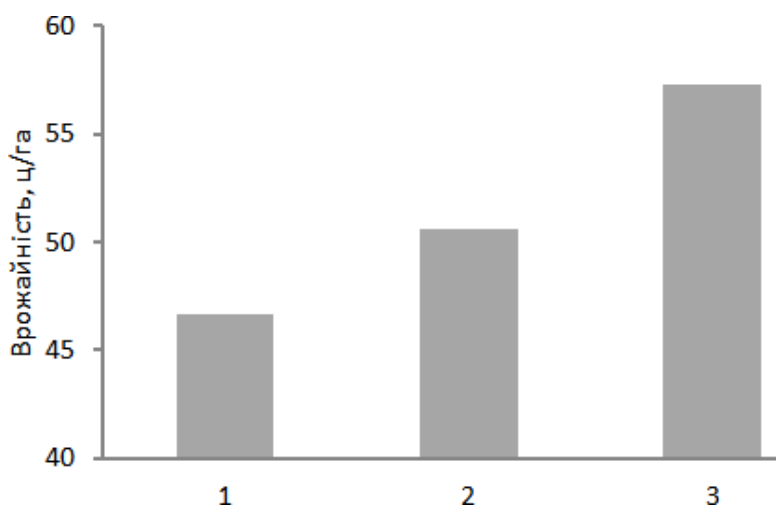

b)

Fig. 2. - Diagram of yield of spring wheat (a) and barley (b) in sowing according to the schemes: I, II $i$ III

Also, studies were carried out on the estimation of the growth of yield in the application of the modernized sowing unit in comparison with the usual preplant treatment of soil without the introduction of 
granular mineral fertilizers and with the continuous surface introduction of the starting dose of fertilizers, followed by pre-sowing cultivation and seeding of seeds, while simultaneously introducing into the soil the main dose of fertilizers. As a result of the conducted researches (Figure 2), it was found that when applying a combined sowing unit for simultaneous sowing with the introduction of the starting and main dose of fertilizers, the yield of spring wheat is 56.4 centners per hectare and barley is 57.3 centner / ha. At the same time, compared to the application of the continuous introduction of the starting norm of fertilizers by the spreading method, pre-sowing cultivation and combined sowing with the simultaneous introduction of the basic norm of fertilizers, the yield of spring wheat increased by 5,1 centners / ha, and barley increased by 6,7 centners / ha. The yield increase in the application of the modernized unit in comparison with sowing without fertilizing is, respectively, for spring wheat $-6.9 \mathrm{c} / \mathrm{ha}$, and for barley $10.6 \mathrm{c} /$ ha.

Taking into account the price of 1 ts of grain crops (as of January 2017), the economic effect of increasing the yield of grain crops for spring wheat is $2652.00 \mathrm{UAH} /$ ha, and for barley it is $3048.50 \mathrm{UAH} / \mathrm{ha}$.

Table 1. - Technological and operational parameters of the combined sowing unit

\begin{tabular}{|l|l|}
\hline Indicator & Value \\
\hline Turning radius, $\mathrm{m}$ & $6,5 \ldots 8,9$ \\
\hline Turn time, $\mathrm{p}$ & $18,4 \ldots 24,7$ \\
\hline Average speed on the turntable, $\mathrm{m} / \mathrm{s}$ & 1,78 \\
\hline $\begin{array}{l}\text { Deviation of the trajectory of the second machine relative to } \\
\text { the trajectory of the first, see: }\end{array}$ \\
when turning & 23,7 \\
when working in motion & 3,6 \\
\hline Specific fuel consumption, I / ha & 3,77 \\
\hline Working time coefficient & 0,85 \\
\hline
\end{tabular}

In conducting field studies according to the standard method, the maneuver and performance indicators of a combined sowing unit (Table 1) were also determined, which confirm the compliance of these indicators with the requirements for efficient seeding.

According to the analysis of the obtained results of field research of quality performance indicators, as well as the estimation of the growth of crop yields due to the use of a combined sowing unit, it is proved that the combining of technological operations of grain crop sowing with the introduction of the starting and main fertilizer dose in one pass of the proposed combined sowing aggregate.

\section{Conclusuons}

As a result of field experimental studies, an increase in the yield of spring wheat and barley was observed when a combined sowing unit was used for simultaneous seeding of grain crops with introduction of the starting and main fertilizer doses to the soil in comparison with known sowing schemes. The obtained results of field studies confirm the feasibility of combining the technological operations of seeding grain crops with the intra-ground introduction of the starting and basic fertilizer standards in one passage of the combined sowing unit.

\section{References}

1. Kabakov N.S. Combined Soil-Cultivating and Sowing Aggregates and Machines / N.S. Kabakov, A.I. Mordukhovich // - M .: Rosselkhozizdat, 1984. - 80 p.

2. Bekhov T.D. Combined machines and aggregates for cultivating agricultural crops / T.D. Bekhov, V.D. Dyachenko // - Minsk: Urojai, 1980. - 200 p. 
3. Vilde A.A. Combined tillage machines / A.A. Vilde, A.Kh. Tsesnieks, Yu.P. Moritis, etc. // - L .: Agropromizdat. Leningr. dept., 1986. $-128 \mathrm{p}$.

4. Skorokhodov A.N. Substantiation of methods for increasing the efficiency of the use of technological complexes in plant growing. The dissertation author's abstract on competition of a scientific degree of the doctor of technical sciences / A.N. Skorokhodov // - Moscow: MGAU, 1997.

5. Shchitov S.V. Decrease in energy costs in sowing operations / S. Shchitov, N.V. Spiridanchuk, E. Reshetnik // Engineering and equipment for the village. - 2012. - №11. - P. 30-32.

6. Petukhov D.A. Efficiency of combining technological operations on the basis of multifunctional sowing units in the cultivation of grain crops / Petukhov D.A., Yurchenko A.V. // Rinok APK. 2012. №4. P. 22-24.

7. Kosolapov V.V. Determination of the efficiency of the seeding machine operation / V.V. Kosolapov, A.N. Skorohov // Sel'skoe mekhanizator. 2012. №10. P. 9-10.

8. Vedenyapin S.V. General methodology of experimental research and processing of experimental data / S.V. Vedenyapin // M., Kolos, 1967, 159 p.

9. Dospehov B.A. Methodology of field experience (with the basics of statistical processing of research results) / B.A. Dospekhov // - M .: Agropromizdat, 1985. - 351 p. 